\title{
Strategies to Attain Faculty Work-Life Balance
}

\author{
Joan Owens, $\mathrm{PhD}, \mathrm{RNC}$ \\ Carol Kottwitz, DNP, PMHNP, PMHCNS, ARNP \\ Jane Tiedt, PhD, RN \\ Jeffery Ramirez, PhD, PMHNP, CARN-AP, ARNP \\ Gonzaga University
}

\begin{abstract}
Background: Achieving work-life balance can be a challenge for academic faculty members. The multifaceted demands and expectations of the role can affect faculty satisfaction and the ability to attain work-life balance. The ever-changing trends in higher education, including technology and online education modalities provide additional factors that can inhibit faculty satisfaction and work-life balance. Aims: This paper explores barriers to achieving work-life balance such as cognitive dissonance, emotional dissonance and burnout. Understanding barriers is essential to developing strategies to promote work-life balance.

Methods: An integrated review of the literature on life balance of academic faculty in all disciplines using multiple online databases.

Conclusion: Strategies, organized around mentoring and self-care, include promoting physical health, connecting socially, and practicing mindfulness as a cognitive approach can help counteract work-place stressors and help in achieving work-life balance.
\end{abstract}

Submitted 20 August 2018: accepted 18 September 2018

Keywords: faculty satisfaction, faculty workload, work-life balance, resilience

Faculty morale, academic pressures, campus climate and culture, working conditions, support services, collegial relationships, and promotion and tenure processes are all elements of faculty work-life in higher education. Achieving work-life balance can be a challenge for senior and mid-career faculty members, but also for newly hired and nontenure track faculty as well. New faculty members often lack preparation and training in the academic role. Although they possess discipline-specific knowledge, skills and scholarship, they are ill-prepared for the demands of teaching, advising, scholarship and academic citizenship. Many new faculty need significant support in teaching and learning practices, mentoring into the role, and help assimilating into the institutional climate and culture (Richardson \& Alsup, 2015). Non-tenure track faculty often carry heavier teaching assignments and have less job security or advancement opportunities (Ott \& Cisneros, 2015). Tenure-track faculty must navigate the complex and unfamiliar process of promotion and tenure. Once tenure is achieved, mid-career faculty are expected to assume more leadership roles and service responsibilities and this leading to greater job dissatisfaction (Mamiseishvili, Miller, \& Lee, 2016; Topp, Hershberger, \& Bratt, 2017). These elements can impact faculty satisfaction and ability to attain work-life balance. Faculty need to identify and utilize skills and tools to not only survive but thrive in the world of higher education. 
This article explores trends in higher education impacting faculty satisfaction and the goal is to provide tools and strategies to enhance work-life balance.

\section{TRENDS IN HIGHER EDUCATION}

Academia is changing from the institutions of higher learning a decade ago. Student demographics are more diverse, and teaching-learning practices are being transformed by technology. These factors can facilitate or inhibit faculty satisfaction and work-life balance. Results from a 2015 Gallup survey of faculty workplace engagement showed that faculty who reported a negative campus climate and hostile work environment experience lower faculty morale, more job dissatisfaction and less faculty engagement; which is a predictor of faculty attrition (Jaschik \& Lederman, 2015). Another area of concern is the growth in non-tenure track (NTT) faculty. Based on an analysis of the Collaborative on Academic Careers in Higher Education (COACHE) national dataset, NT'T faculty are becoming the majority in higher education (Ott \& Cisneros, 2015). This leads to structural inequities within academic institutions. NTT faculty are less satisfied and report being treated like second-class citizens (Kezar, 2013). NTT faculty experience heavier workloads, less autonomy or opportunities for advancement, hierarchical inequality and job insecurity (Ott \& Cisneros, 2015).

Job stress is noted for tenure-track faculty and midcareer tenured faculty as well. A 2013 - 2014 national survey of undergraduate faculty, noted similar issues with work-life integration, lack of support for developing research agendas and teaching skills, lack of collaboration, and uncertainty regarding tenure, reappointment and promotion processes, role expectations and lack of a collegial relationships (Eagan et al., 2014). These factors are likely to hinder faculty success and job satisfaction. Predictors of faculty success include realistic role expectations, work-life balance, and a positive collegial environment (Stupnisky, Weaver-Hightower, \& Kartoshkina, 2015). Factors that incentivize or disincentivize job satisfaction with the academic role include the amount of time devoted to different elements of the job, quality of students and facilities and available support services and resources (Touranguea, Wong, Saari, \& Patterson, 2013). Since faculty are a major resource within academic institutions, this level of dissatisfaction and lack of engagement is concerning and needs to be addressed (Curnalia \& Mermer, 2018)

\section{Student Demographics}

Demographics of college students are shifting away from the traditional 18-24-year-old profile to include older, nontraditional, diverse and first-generation student learners. Schools are experiencing a flattening, and in some cases, declining enrollment. Nationally, college enrollment from 2010 - 2015 decreased by 5\% and the number of part-time students increased by 15\%. High school graduates are expected to decline over the next decade (Carter et al., 2012). As a result, we are seeing more institutional commitment to student equity and inclusion of first generation, nontraditional, low income and minority students (Bransberger \& Michelau, 2016; Hainline, Gaines, Long Feather, Padilla, \& Terry, 2010).

\section{Technology and Online Education}

One of the most pervasive trends on college campuses today is the integration of technology in the classroom and tremendous growth in distance education (Allen \& Seaman, 2014). Nationwide, undergraduate enrollment has decreased from 17.3 million in 2014 to 17 million in 2015. During that same time, enrollment in distance education 
courses increased from $27.7 \%$ to $29 \%$ and enrollment in exclusively online programs increased from $12.1 \%$ to $12.3 \%$ (McFarland et al., 2017; Snyder, De Brey, \& Dillow, 2018). While technology is revolutionizing higher education, faculty attitudes toward and motivation to engage in online education merits further discussion.

As the number of online courses and student demands for quality tech-savvy instruction increases, faculty are required to learn new teaching pedagogies and learning platforms for this shifting education paradigm (Carter et al., 2012; Edwards, Perry, \& Janzen, 2011). Online teaching is often an expectation for non-tenure track and adjunct faculty and yet faculty receive inadequate preparation, training and technological support (Seirup, Tirotta, \& Blue, 2016). Faculty perceptions of online courses range from being dehumanizing, inferior, frustrating, difficult, timeintensive and not effective to offering flexibility, unlimited opportunities and increasing access to education (Chiasson, Terras, \& Smart, 2015; Merillat \& Scheibmeir, 2016; Panda \& Mishra, 2007). Most concerning is the numerous studies reporting faculty experiences and perceptions of teaching online as much more time and labor intensive for both course development and instruction time (Allen \& Seaman, 2009; Chiasson et al., 2015: Merillat \& Scheibmeir, 2016). This is an additional barrier for attaining work-life balance.

\section{WORK-LIFE BALANCE}

Understanding life balance is essential for addressing the ability of an educator to survive and thrive under the pressure of multi-faceted academic demands. These demands may limit a faculty members ability to spend time on needs they deem important to them, thus limiting the potential to achieve life balance. The demands on academic faculty lead to high stress, which may affect the achievement of balance between work and life roles (Eagan et al., 2014). According to Grant-Vallone and Ensher (2017), faculty believe life balance may not be attainable and is always in a state of flux.

\section{Life Balance}

The terms life balance and work-life balance are used broadly and with slightly varied definitions in the literature. Based on a comprehensive literature synthesis on the conceptual definition of work-life balance, Casper, Vaziri, Wayne, DeHauw, and Greenhaus (2018) concluded that work-life balance is a self-appraisal of how well one combines work with non-work roles. Similarly, Greenhaus \& Allen (2011) define life balance as a multi-modal approach derived from a sense of effectiveness and satisfaction in multiple life roles. Work-life balance can be further defined as a transition toward flexible and fluid boundaries between one's work and life outside of the workplace (Sorenson, 2017), which correlates with the life balance definition most applicable to educators, the ability to manage external pressure from a competitive work environment with leisure and or family (Khallash \& Kruse, 2012).

\section{Life Balance in Academic Faculty}

Faculty responsibilities include teaching, advising, research, and service. The wide range of roles inherent in the work of academic faculty from all disciplines, can affect the ability to find a balance. On average, faculty work over 56 hours per week (Steinberg, 2017). Faculty members often work beyond required loads due to the demands of university and of research requirements. Bentley \& Kyvik (2013) studied faculty work hours in 13 countries. Faculty in the United States spend an average of 17.6 hours per week solely on the research component of their workload. Additionally, the demands of ever-changing technology, increasing diversity of students, and the tightening fiscal resources for 
higher education, are just a few of the changes which affect the faculty role and ability to achieve and maintain life balance (Curnalia \& Mermer, 2018).

Wilton and Ross (2017) looked at work-life balance for academic faculty by exploring challenges of balancing career demands and family in a small, undergraduate, teaching intensive campus in Canada. The participants of the study comprised $36 \%$ of the total faculty and $54 \%$ of the faculty with children employed at the campus. Three major themes emerged from the qualitative interviews: Flexibility, sacrifice, and insecurity. Issues identified by participants as problematic, such as tenure and promotion, faculty evaluations, and the focus on research are foundational to academia. Although the theme of flexibility was positive in the participant's reports regarding working hours and choice of research, the flexibility to work from home and work after hours contributed to the perception that the work is never really completed. The theme of insecurity included the pre-tenure process and a general lack of clear expectations in academia. Participants highlighted a "cutthroat culture that is very competitive and not fostering successful family life" (Wilton \& Ross, 2017, p. 80). This competitive culture added to the burden of sacrifice. The researchers noted that all participants felt they had made sacrifices, especially related to research and work-related travel. In this study, female participants reported more sacrifice and less balance than the male faculty members, although the difficulty in obtaining an acceptable work-life balance existed for both genders (Wilton \& Ross, 2017). Additional burdens for women in academia have been noted on other studies as well (Gardner, 2012; Howe-Walsh \& Turnbull, 2014) particularly related to the competitive nature of faculty in the STEM disciplines (Ruder, Plaza, Warner, \& Bothwell, 2018) and faculty incivility in nursing and other health sciences (Griffin \& Clark, 2014; Peters, 2014; Wright \& Hill, 2015).

In a study designed to examine faculty work and family conflict, Fox, Fonseca, and Bao (2010) surveyed 765 science and engineering faculty from nine Research I labeled universities. The findings included a bidirectional conflict of work and family. Faculty respondents noted that work interfered with family more than family interfering with work. Specifically, $76.7 \%$ of the respondents reported that work interfered with family life. There was a slight gender difference, although as with Wilton and Ross's (2017) research, both genders reported that work interfered with family at a high rate. The female respondents had a mean level of conflict of work with family of 3.19 compared to a mean of 2.89 for the male respondents. The study also found that faculty with a senior rank increases the likelihood of family to work interference, but decreases the work to family conflict, potentially because the research competition decreases as faculty reach senior rank. Fox et al. (2010) also found that the specific faculty field of teaching has no effect on reported levels of work family interference. However, the competitive climate of research and the perception of the level of competition was highly indicative of work to family conflict, indicating that faculty members have a difficult time managing pressure from the competitive work environment with family, decreasing the ability to achieve life balance.

The high stress of academia and its relation to work-life balanced was also discussed by Yordy (2018). The study evaluated data from the 2013 - 2014 Higher Education Research Institute (HERI) Faculty Survey of 10, 019 full time faculty teaching at universities across the United States. The study sought to determine if high levels of career related stress affected faculty members' work-life balance by analyzing the relationship of career related stress and achievement of a healthy work-life balance. The results found that six variables significantly predicted the inability to attain a healthy work-life balance for faculty. The lack of personal time, self-imposed high expectations, committee work, research/publishing demands, institutional procedures, and colleagues create stress that influences work-life balance in faculty. 


\section{BARRIERS TO ACHIEVING WORK-LIFE BALANCE}

Researchers have examined the constructs of cognitive and emotional dissonances to explain and describe the discord leading to job satisfaction or dissatisfaction. Emotional experiences, burnout and job satisfaction play a critical role in turnover (Lee \& Chelladurai, 2017). Employees who display emotions that are incongruent with feelings as educators do, experience the emotional exhaustion component of job burnout (Kenworthy, Fay, Frame, \& Petree, 2018). Cognitive and emotional dissonances have been used to explain and describe the personal discord that leads to job dissatisfaction (Davies, Van der Heijden, \& Flynn, 2017). This can contribute to the belief among academics that life balance is not possible in the role.

\section{Cognitive Dissonance}

Tensions between job demands, perceived level of control, climate and culture of the work environment can lead to incongruity and discord (Karanika-Murray, Michaelides, \& Wood, 2017). Festinger's (1957) historic work on cognitive dissonance explained that people, "attempt to establish internal harmony, consistency, or congruity among their opinions, attitudes, knowledge and values" (p. 260). Festinger further states that cognitive dissonance causes psychological discomfort leading to motivation and the reduction of dissonance, in other words, inconsistencies of competing forces. An example of cognitive dissonance applied to academic faculty whose various roles include teaching, research, service, and publishing, all of which compete for time with the family.

The research on academic faculty regarding cognitive dissonance is sparse. A study by Fontenot, Hawkins, and Weiss (2012), concluded that nurse practitioner faculty experience cognitive dissonance because of the competing forces of job expectations versus how they are rewarded. For example, the participants reported the number of hours they work is not reflected in the salary they receive as compared to working in practice. In addition, this study identified the inconsistences between the expectations of faculty and administration. In a study of 734 academic scientists in the United Kingdom, Lam (2010) noted a growing discord between role expectations for scientists between their traditional academic roles and desires to be innovative researchers contributing to industry. In business schools, researchers have found that published school rankings against competitors or national benchmarks and scientific journal rankings for faculty publications can create tension between faculty and administration resulting in cognitive dissonance (Kodeih \& Greenwood, 2013; Malsch \& Tessier, 2014)

\section{Emotional Dissonance}

Hochschild (2012), a social scientist, explained that emotional dissonance occurs when one must display organizational emotions even if they genuinely feel other emotions. Studies have concluded emotional dissonance leads to stress, burnout and negative health consequences (Cheung \& Cheung, 2013; Cheung \& Tang, 2012). Cheung and Tang's study supported previous research relating emotional dissonance to burnout. They identified three dimensions of burnout which includes emotional exhaustion, depersonalization, and lack of personal accomplishment.

Cheung and Tang (2012) examined the relationship of emotional dissonance and work-family interference. They concluded that there was a positive correlation between strain-based work-family interference and emotional dissonance. Strain-based work-family interference occurs when the demands in one role intrudes into and interferes with participating in another role, depleting personal resources (Nohe, Meier, Sonntag, \& Michel, 2015). Finally, Cheung and Tang (2012), reported that employees experiencing high levels of emotional dissonance tend to 
experience more negative emotions leading to dissatisfaction with work and interfering with family relationships. As Cheung \& Tang (2012) note, emotional dissonance is bound to affect the family relationships which leads to family conflicts and added stress levels.

\section{Burnout}

Padilla and Thompson (2016) surveyed university faculty $(N=1,439)$ examining job satisfaction. Some of the factors leading to burnout among faculty are long working hours, demanding job duties including research, service, teaching, and grant preparation. They concluded that $27 \%$ of their participants reported they often experienced burnout. The main reasons faculty experienced burnout was the number of required hours worked led to decreased hours with family, loss of leisure activities, and less quality sleep. These studies have demonstrated that individuals who experience cognitive and emotional dissonance are at risk for elevated stress levels and burnout. The person's perception of the experience as stressful triggers a host of neurochemical changes in the body. Chronic activation of this stress response can lead to maladaptation, accelerated aging, and a host of health consequences including high blood pressure, diabetes, and heart disease (Tiedt, 2015).

\section{STRATEGIES FOR PROMOTING WORK-LIFE BALANCE}

When burnout becomes a threat or reality, faculty should employ strategies to promote self-care, enhance resilience and restore faculty vitality for their work. As previously defined, life balance includes a multi-modal approach to wellbeing. It involves the management of roles, stress, cognition and emotion to successfully adapt to life's challenges. Similarly, Tabibnia and Radecki (2018) have broadly defined resilience as the ability to successfully adapt to adversity. Planning strategies, stress, cognitions, and emotions are all regulated by the brain. Neuroscience research includes empirical evidence for techniques and strategies that cause long-term psychological or physical health benefits by boosting neuroplasticity, well-being, and resilience in adults (Tabibnia \& Radecki, 2018). Employee resilience training is organized around physical health, connecting socially, and cognitive approaches, which help to create a balanced lifestyle leading to achieving work-life balance as a whole (Robertson, Cooper, Sarkar, \& Curran, 2015).

\section{Self-Care Strategies}

Physical Health. Sleep, exercise, and diet are elements of physical health that improves emotional well-being and resilience. For example, skipping just one night of sleep leads to neurological changes that compromise the brain's ability to execute tasks and regulate emotion, leading to more impulsive reactions to negative experiences (Anderson \& Platten, 2011). Developing a routine of healthy sleep habits requires addressing multiple practices or lifestyle habits that interfere with sleep. The Centers for Disease Control and Prevention (2018) lists the following essential health sleep habits:

- Keep a consistent sleep schedule, getting up and going to bed at the same time every day, even on weekends and vacations.

- Establish a relaxing bedtime routine (e.g., warm shower, herbal tea, small snack, decrease exposure to bright light by turning off electronic devices at least 30 minutes before bed).

- Avoid consuming alcohol before bedtime and caffeine late afternoon or evening.

- Avoid going to bed unless you are sleepy. 
- If you are not asleep after 20 minutes, get out of bed.

- Limit daytime napping.

- Avoid consuming a large meal before bedtime.

- Keep the bedroom cool, comfortable, quiet and relaxing.

- Control cognitions or thoughts that worry you by employing relaxation techniques like guided imagery or breathing.

There are many positive effects of regular exercise on our physical health including the lowering of heart disease risk, expanding lung capacity, reducing excess weight, reducing risk of falls or fractures, and other physical improvements (Childs \& De Witt, 2014). Athletes, however, have long reported a boost in mood with vigorous exercise. Nagahara and Tuszynski (2011), found that physical exercise is responsible for releasing brain-derived neurotrophic factor. This protein is responsible for connectivity, neural plasticity and neurogenesis in multiple brain regions which play a critical role in memory and learning but also regulating stress. It is important to note that all exercise is not created equal. Specifically, aerobic exercise supports neuronal growth in the hippocampus which lends itself to enhanced mood and resilience (Cotman, Berchtold, \& Christie, 2007). The Global Council on Brain Health (2016) recommends the following:

- 150 minutes of moderate-intensity aerobic activity each week as well as two or more days of musclestrengthening activities.

- Evaluating your current activities and exercises and doing more, particularly if it's outdoors (unless you are already extremely active).

- Use the stairs instead of the elevator.

- Try new physical exercise and activities that you think you will enjoy.

- Challenge yourself a little bit more over time.

- Stay motivated and consider doing physical activities with other people.

- Try to keep moving throughout the day

- Be patient and persistent.

Diet is another component of physical health that can contribute to overall well-being. Broad dietary strategies for building greater resilience to stress include dietary caloric restriction while maintaining specific nutrition patterns (Redman \& Ravussin, 2011). These strategies improve brain-derived neurotrophic factor production and therefore decrease inflammation, oxidative damage and dysfunctional proteins. The improved brain derived neurotrophic factor production results in improved mood and cognition as well as delayed aging and its associated diseases (Longo \& Mattson, 2014). According to Sarris et al. (2015), the Mediterranean diet has the strongest data for supporting brain health. This diet consists primarily of vegetables, fruits, seafood, whole grains, lean meats, nuts, olive oil, and moderate consumption of red wine.

Connecting Socially. Positive social connectedness can have long-term effects on the central nervous system (Hari, Henriksson, Malinen, \& Parkkonen, 2015). Chronic social isolation has shown to increase stress and hypothalamic-pituitary axis activation which can lead to brain cell loss in the medial prefrontal cortex and abnormal cell growth in the amygdala. In turn, these are the brain structures that regulate mood and decision-making (Hari et 
al., 2015). In a study by Sherman, Cheng, Fingerman, and Schnyer (2015), perceived social support was correlated with positive brain changes in the medial prefrontal cortex and amygdala. In addition, social support has long been associated with lower risk for depression, anxiety, post-traumatic stress disorder, and stress-related medical conditions (Pietromonaco \& Collins, 2017).

Expressing gratitude can have long term effects on subjective well-being. In a study by Kini, Wong, McInnis, Gabana, \& Brown (2016), engaging in an exercise of writing a letter of gratitude had lasting effects on the medial prefrontal cortex three months later. This has implications for emotion regulation, social reward, and empathy. In addition, daily journaling of gratitude for two weeks increased life-satisfaction and reduced anxiety (Kerr, O'Donovan, \& Pepping, 2015).

Cognitive Training. The way in which one experiences events or situations is guided by our thoughts about these events. Resilience is strongly associated with the ability to monitor for automatic negative thoughts and replace them with positive ones (McRae, Ciesielski, \& Gross, 2012). This is called cognitive reappraisal or reframing. By replacing negative thoughts with positive ones, (e.g., like viewing a lengthy traffic jam as an opportunity to listen to a podcast) we can modulate the associated negative emotion and decrease stress.

The act of identifying or labeling our emotions can reduce the impact of negative emotion. Putting feelings into words (e.g., I am angry) can have lasting benefits by reducing autonomic or physiological responses when thinking of the event (Tabibnia, Leiberman, \& Craske, 2008). Using language to express emotion can lead to deeper appraisal of the emotion and thoughts related to the emotion. This paves the way for deeper cognitive reframing and emotional regulation and boosting resilience and well-being.

Mindfulness is another strategy for cognitive training and increasing the sense of well-being. It is commonly described as the act purposefully paying attention to the present moment without judgment (Crane, Brewer, Feldman, \& Kabat-Zinn, 2017). Mindfulness practices have been associated with the improvement of attention, positive emotion and sense of well-being, and improved relationship quality (Gu, Strauss, Bond, \& Kavanagh, 2015). Neurological changes because of mindfulness practice include structural and functional changes in the prefrontal cortex and amygdala suggesting improved emotional regulation (Guendelman, Medeiros, \& Rampes, 2017).

Literature supports mindfulness meditation such as focused breathing, the body scan, and loving-kindness compassion practices as a means of reducing anxiety and depression, and improving focus, attention, and emotion regulation (Davis \& Hayes, 2011). Resilience building strategies are interactive and have an additive effect. Practicing and employing multiple strategies strengthens important neural pathways that increase the likelihood of stress resilience. While one strategy may have mild to moderate effect, they each are important in supporting the scaffold of building stress resilience (Southwick \& Charney, 2012).

\section{Work-Place Strategies}

The workplace culture is one of the most important factors surrounding an employee's commitment and engagement to the job (Brunges \& Foley-Brinza, 2014). In the academic setting, it is crucial to have a positive and collegial environment (Stupnisky, Weaver-Hightower, \& Kartoshkina, 2015) to decrease the incidence of burnout. The ideal working environment is one that is not only safe, but free of incivility, and full of collaboration (Raziq \& Maulabakhsh, 2015). An environment that fosters collegiality and community-building, open communication, and mutual respect may assist faculty in finding the ideal balance in their work and life roles. 
Faculty development and mentoring are critical for successful adaptation to the academic role as well as important to faculty satisfaction. New faculty may be ill prepared for classroom or online instruction and are likely to be unfamiliar with instructional or pedagogical methods (Clinefelter, 2012). Faculty development should include an orientation to the institution with clear delineation of expectations for teaching, service, and scholarship. Additionally, the organization should provide a variety of training opportunities to promote teaching-self efficacy and skill development (Stupnisky, Weaver-Hightower, \& Kartoshkina, 2015). Role development and mentorship is utilized to promote faculty retention and satisfaction (National League for Nursing, 2018). These methods are used to foster a positive work environment.

Both novice and mid-career faculty benefits from mentoring relationships. For new faculty, mentoring is a formal, structured process with clear goals and expectations using appropriately matched mentor-mentee pairs. This dyad helps the new faculty member assimilate to the new academic environment and build connections across the organization. Helping the new faculty member socialize into his/her role provides a sense of legitimacy to the mentee (Potter \& Tolson, 2014). Some institutions use multiple mentors to address different needs such as orientation, career planning, developing teaching skills, or research and scholarship. Senior faculty can be sought out for career guidance and support from within the organization but would not necessarily need to be discipline-specific, whereas a researchmentor should be someone within a shared discipline skilled in research and scholarship. They provide networking opportunities, guidance for developing a research trajectory, and advice on scholarly dissemination (Feldman, Arean, Marshall, Lovett, \& O'Sullivan, 2010). Mid-career faculty mentoring can be either formal or informal. It tends to be more fluid based on the mentee's needs; often focusing on leadership development, innovations, and strategies to prevent burnout and keep the passion for teaching alive (Feldman et al., 2010).

The mentoring model is not without challenges. There is a lack of incentive or recognition for the senior faculty members to assume a mentoring role. Additionally, with the trend in higher education to hire more non-tenure track faculty, there are insufficient numbers of experienced faculty to provide mentoring, or they become burdened by the sheer number of new faculty needing support which fuels their own workload burden (Barrett, Mazerolle, \& Nottingham, 2017; Potter \& Tolson, 2014).

\section{SUMMARY}

Academic faculty have a wide range of roles inherent in their work, independent of rank or tenure that affect the ability to achieve and maintain work-life balance. Cognitive and emotional dissonance create a risk for elevated stress levels and burnout among faculty members. In addition, the stressful triggers also create neurochemical changes in the body that can lead to health issues beyond the inability to experience a balanced life. Committing to self-care and workplace strategies can strengthen stress resilience and improve faculty satisfaction and the ability to attain work-life balance. 


\section{REFERENCES}

Anderson, C., \& Platten, C.R. (2011). Sleep deprivation lowers inhibition and enhances impulsivity to negative stimuli. Behavioural Brain Research, 217, 463-466. https://doi.org/10.1016/j.bbr.2010.09.020

Allen, I.E., \& Seaman, J. (2009). Learning on demand: Online education in the United States. Babson Park, MA: Babson Survey Research Group. Retrieved from https:// files.eric.ed.gov/fulltext/ED529931.pdf

Allen, I.E., \& Seaman, J. (2014). Grade change: Tracking online education in the United States. Babson Park, MA: Babson Survey Research Group. Retrieved from https://www.onlinelearningsurvey.com/reports/gradechange.pdf

Barrett, J.L., Mazerolle, S.M., Nottingham, S.L. (2017). Attributes of effective mentoring relationships for novice faculty members: Perspectives of mentors and mentees. Athletic Training Education Journal, 12(2), 152-162. https://doi.org/10.4085/1202152

Bentley, P., \& Kyvik, S. (2013). Individual differences in faculty research time allocations across thirteen countries. Research in Higher Education, 54(3), 329-348. https:/ / doi.org/10.1007/s11162-012-9273-4

Bransberger, P., \& Michelau, D.K. (2016). Knocking on the college door: Projections of high school graduates. Boulder, CO: Western Interstate Commission for Higher Education. Retrieved from https://knocking.wiche.edu/reports/privates

Brunges, M., \& Foley-Brinza, C. (2014). Projects for increasing job satisfaction and creating a healthy work environment. AORN Journal, 100(6), 670-681. https://doi.org/10.1016/j.aorn.2014.01.029

Carter, L., Salyers, V., Page, A., Williams, L., Albl, L., \& Hofsink, C. (2012). Highly relevant mentoring (HRM) as a faculty development model for web-based instruction. Canadian Journal of Learning and Technology, 38(1), 1-16. Retrieved from http://hdl.handle.net/11205/138

Casper, W., Vaziri, H., Wayne, J., DeHauw, S., \& Greenhaus, J. (2018). The jingle-jangle of work-nonwork balance: A comprehensive and meta-analytic review of its meaning and measurement. Journal of Applied Psychology, 103(2), 182-214. https://doi.org/10.1037/ap10000259

Centers for Disease Control and Prevention. (2018). Are you getting enough sleep? https://www.cdc.gov/features/sleep/

Childs, E., \& De Wit, H. (2014). Regular exercise is associated with emotional resilience to acute stress in healthy adults. Frontiers in Physiology, 5, 161. https://doi.org/10.3389/fphys.2014.00161

Cheung, F. Y., \& Cheung, R. Y. (2013). Effect of emotional dissonance on organizational citizenship behavior: Testing the stressor-strain-outcome model. The Journal of Psychology, 147(1), 135-8. https://doi.org/10.1080/00223980.2012.676576

Cheung, F. Y., \& Tang, C. S. (2012). The effect of emotional dissonance and emotional intelligence on work-family interference. Canadian Journal of Behavioral Science, 44(1), 50-58. https://doi.org/10.1037/a0025798

Chiasson, K., Terras, K., \& Smart, K. (2015). Faculty perceptions of moving a face-to-face course to online instruction. Journal of College Teaching and Learning, 12(4), 231-240. https://doi.org/10.19030/tlc.v12i3.9315 
Clinefelter, D. (2012). Best practices for online faculty development. Retrieved from https://www.learninghouse.com/wpcontent/uploads/2017/09/Best-Practices-for-Online-Faculty-Development_Web_Final.pdf

Cotman, C.W., Berchtold, N.C., \& Christie, L. (2007). Exercise builds brain health: Key roles of growth factor cascades and inflammation. Trends in Neurosciences, 30(9), 464-472.

https://doi.org/10.1016/j.tins.2007.06.011

Crane, R.S., Brewer, J., Feldman, C., \& Kabat-Zinn, J. (2017). What defines mindfulness-based programs? The warp and the weft. Psychological Medicine, 47(6), 990-999. https://doi.org/10.1017/S0033291716003317

Curnalia, M., \& Mermer, D. (2018). Renewing our commitment to tenure, academic freedom, and shared governance to navigate challenges in higher education. Review of Communication, 18(2), 129-139. https://doi.org/10.1080/15358593.2018.1438645

Davies, E., Van der Heijden, B., \& Flynn, M. (2017). Job satisfaction, retirement attitude and intended retirement age: A conditional process analysis across workers' level of household income. Frontiers in Psychology, 8, 891. https://doi.org/10.3389/ fpsyg.2017.00891

Davis, D. M. \& Hayes, J. A. (2011). What are the benefits of mindfulness? A practice review of psychotherapy related research. Psychotherapy, 48(2), 198-208. https://doi.org/10.1037/a0022062

Eagan, M.K., Stolzenberg, E.B., Lorzano, J., Aragon, M.C., Schard, M.R., \& Hurtado, S. (2014). Undergraduate teaching faculty: the 2013-2014 HERI faculty survey. Los Angeles: Higher Education Research Institute, UCLA. Retrieved from https://www.heri.ucla.edu/monographs/HERI-FAC2014-monograph-expanded.pdf

Edwards, M., Perry, B., \& Janzen, K. (2011). The making of an exemplary online educator. Distance Education, 32(1), 101-108. https://doi.org/10.1080/01587919.2011.565499

Feldman, M.D., Arean, P.A., Marshall, S.J., Lovett, M., \& O’Sullivan, P. (2010). Does mentoring matter: Results from a survey of faculty mentees at a large health sciences university. Medical Education Online, 15: 5063. https://doi.org/10.3402/meo.v15i0.5063

Festinger, L. (1957). A Theory of Cognitive Dissonance. Palo Alto, CA: Stanford University Press.

Fontenot, H. B., Hawkins, J. W., \& Weiss, J. A. (2012). Cognitive dissonance experience by nurse practitioner faculty. Journal of the American Academy of Nurse Practitioners, 24(8), 506-513. https://doi.org/10.1111/j.17457599.2012.00726.x

Fox, M., Fonseca, C., \& Bao, J. (2011). Work and family conflict in academic science: Patterns and predictors among women and men in research universities. Social Studies of Science, 41(5), 715-735. https://doi.org/10.1177/0306312711417730

Gardner, S.K. (2012). "I couldn't wait to leave the toxic environment": A mixed methods study of women faculty satisfaction and departure from one research institution. NASPA Journal about Women in Higher Education, 5(1), 71-95. https://doi.org/10.1515/njawhe-2012-1079

Global Council on Brain Health (2016). The brain-body connection: GCBH recommendations on physical activity and brain bealth. https://doi.org/10.26419/pia.00013.001 
Grant-Vallone, E., \& Ensher, E., (2017) Re-crafting careers for mid-career faculty: A qualitative study. Journal of Higher Education Theory and Practice, 17(5), 10-24. Retrieved from http:/ /www.m.www.nabusinesspress.com/JHETP/GrantValloneEJ_17_5_.pdf

Greenhaus, J. H., \& Allen, T. D. (2011). Work-family balance: A review and extension of the literature. In J. C. Quick, \& L. E. Tetrick (Eds.), Handbook of occupational health psychology (2nd ed). Washington, DC: American Psychological Association.

Greenhaus, J. H., \& Beutell, N., J. (1985). Sources and conflict between work and family roles. Academy of Management Review, 10(1), 76-88. https://doi.org/10.5465/amr.1985.4277352

Griffin, M., \& Clark, C. (2014). Revisiting cognitive rehearsal as an intervention against incivility and lateral violence in nursing: 10 years later. The Journal of Continuing Education in Nursing, 45(12), 535-542. https://doi.org/10.3928/00220124-20141122-02

Gu, J., Strauss, C., Bond, R., \& Cavanagh, K. (2015). How do mindfulness-based cognitive therapy and mindfulnessbased stress reduction improve mental health and wellbeing? A systematic review and meta-analysis of mediation studies. Clinical Psychology Review, 37, 1-12. https://doi.org/10.1016/j.cpr.2015.01.006

Guendelman, S., Medeiros, S., \& Rampes, H. (2017). Mindfulness and emotion regulation: Insights from neurobiological, psychological, and clinical studies. Frontiers in Psychology, 8, 220. https://doi.org/10.3389/fpsyg.2017.00220

Hainline, L., Gaines, M., Long Feather, C., Padilla, E., \& Terry, E. (2010). Changing students, faculty and institutions in the twenty-first century. PeerReview, 12(3). Retrieved from https://www.aacu.org/publicationsresearch/periodicals/changing-students-faculty-and-institutions-twenty-first-century

Hari, R., Henriksson, L., Malinen, S., \& Parkkonen, L. (2015). Centrality of social interaction in human brain function. Neuron, 88(1), 181-193. https:// doi.org/10.1016/j.neuron.2015.09.022

Hochschild, A. R., (2012). The managed heart: Commercialization of human feeling (2 ${ }^{\text {nd }}$ ed.). Los Angeles: University of California Press.

Howe-Walsh, L., \& Turnbull, S. (2016). Barriers to women leaders in academia: Tales from science and technology. Studies in Higher Education, 41(3), 415-428. https:/ / doi.org/10.1080/03075079.2014.929102

Jaschik, S., \& Lederman, D. [Eds.], (2015). The 2015 Inside Higher Ed survey of college and university faculty workplace engagement. Washington DC: Inside Higher Ed \& Gallup. Retrieved from https://www.insidehighered.com/special-reports?page=3\#surveys_data

Karanika-Murray, M., Michaelides, G., \& Wood, S.J. (2017). Job demands, job control, psychological climate, and job satisfaction: A cognitive dissonance perspective. Journal of Organizational Effectiveness: People and Performance, 4(3), 238-255. https://doi.org/10.1108/JOEPP-02-2017-0012

Kenworthy, J., Fay, C., Frame, M., \& Petree, R. (2014). A meta-analytic review of the relationship between emotional dissonance and emotional exhaustion. Journal of Applied Social Psychology, 44(2), 94-105. https://doi.org/10.1111/jasp.12211

Kerr, S. L., O’Donovan, A., \& Pepping, C. A., (2015). Can gratitude and kindness interventions enhance well-being in a clinical sample? Journal of Happiness Studies, 16(1), 17-36. https://doi.org/10.1007/s10902-013-9492-1 
Kezar, A. (2013). Examining non-tenure track faculty perceptions of how departmental policies and practices shape their performance and ability to create student learning at four-year institutions. Research in Higher Education, 54(5), 571-598. https://doi.org/10.1007/s11162-013-9288-5

Khallash, S., \& Kruse, M. (2012). The future of work and work-life balance 2025. Futures, 44(7), 678-686. https://doi.org/10.1016/j.futures.2012.04.007

Kini, P., Wong, J., McInnis, S., Gabana, N., \& Brown, J.W. (2015). The effects of gratitude expression on neural activity. Neuroimage, 128, 1-10. https://doi.org/10.1016/j.neuroimage.2015.12.040

Kodeih, F., \& Greenwood, R. (2013). Responding to institutional complexity: The role of identity. Organization Studies, 35(1), 7-39. https://doi.org/10.1177/0170840613495333

Lam, A. (2010). From 'Ivory Tower traditionalists' to 'entrepreneurial scientists'? Academic scientists in fuzzy university-industrial boundaries. Social Studies of Science, 40(2), 307-340. https://doi.org/10.1177/0306312709349963

Lee, Y., \& Chelladurai, P. (2017): Emotional intelligence, emotional labor, coach burnout, job satisfaction, and turnover intention in sport leadership, European Sport Management Quarterly, 18(4), 393-412. https://doi.org/10.1080/16184742.2017.1406971

Longo, V., \& Mattson, M. P. (2014). Fasting: Molecular mechanisms and clinical applications. Cell Metabolism, 19(2), 181-192. https://doi.org/10.1016/j.cmet.2013.12.008

Malsch, B., \& Tessier, S. (2014). Journal ranking effects on junior academics: Identity fragmentation and politicization. Critical Perspectives on Accounting, 26(2) 84-98. https://doi.org/10.1016/j.cpa.2014.02.006

Mamiseishvili, K., Miller, M.T., \& Lee, D. (2016). Beyond teaching and research: Faculty perceptions of service roles at research universities. Innovations in Higher Education, 41, 273-285. https://doi.org/10.1007/s10755015-9354-3

McRae, K., Ciesielski B., \& Gross J. J. (2012). Unpacking cognitive reappraisal: Goals, tactics, and outcomes. Emotion, 12(2), 250-255. https://doi.org/10.1037/a0026351

McFarland, J., Hussar, B., De Brey, C., Snyder, T., Wang, X., Wilkinson-Flicker, S., ...Hinz, S. (2017). The condition of education 2017 [NCES 2017-144]. Washington DC: National Center for Education Statistics. Retrieved from https://nces.ed.gov/pubs2017/2017144.pdf

Merillat, L., \& Scheibmeir, M. (2016). Developing a quality improvement process to optimize faculty success. Online Learning, 20(3), 159-172. https://doi.org/10.24059/olj.v20i3.977

Nagahara, A. H., \& Tuszynski, M. H. (2011). Potential therapeutic uses of BDNF in neurological and psychiatric disorders. Nature Reviews Drug Discovery, 10, 209-219. https://doi.org/10.1038/nrd3366

National League for Nursing. (2018). Healthful work environment toolkit. New York: Author. Retrieved from http://www.nln.org/docs/default-source/professional-development-programs/healthful-workenvironment-toolkit.pdf?sfvrsn=20 
Nohe, C., Meier, L., Sonntag, K., \& Michel, A. (2015). The chicken or the egg? A meta-analysis of panel studies of the relationship between work-family conflict and strain. Journal of Applied Psychology, 100(2), 522-536. https://doi.org/10.1037/a0038012

Ott, M., \& Cisneros, J. (2015). Understanding the changing faculty workforce in higher education: A comparison on full-time non-tenure track and tenure line experiences. Education Policy Analysis Archives, 23(90). https://doi.org/10.14507/epaa.v23.1934

Padilla, M. A., \& Thompson, J. N. (2016). Burning out faculty at doctoral research universities. Stress and Health, 32(5) 551-558. https://doi.org/10.1002/smi.2661

Panda, S., \& Mishra, S. (2007). E-learning in a mega open university: Faculty attitudes, barriers, and motivators. Educational Media International, 44(4), 323-338. https:/ / doi.org/10.1080/09523980701680854

Peters, A.B. (2014). Faculty to faculty incivility: Experiences of novice nurse faculty in academia. Journal of Professional Nursing, 30(3), 213-227. https://doi.org/10.1016/j.profnurs.2013.09.007

Pietromonaco, P. R., \& Collins, N. L. (2017). Interpersonal mechanisms linking close relationships to health. American Psychologist, 72(6), 531-542. https://doi.org/10.1037/amp0000129

Potter, D.R., \& Tolson, D. (2014). A mentoring guide for nursing faculty in higher education. International Journal of Caring Sciences, 7(3), 727-732. Retrieved from http://internationaljournalofcaringsciences.org/ docs $/ 4 . \% 20$ Potter $\% 20 \% 20$ REVIEW.pdf

Raziq, A., \& Maulabakhsh, R. (2015). Impact of working environment on job satisfaction. Procedia Economics and Finance, 23, 717-725. https://doi.org/10.1016/S2212-5671(15)00524-9

Redman, L. M., \& Ravussin, E. (2011). Caloric restriction in humans: Impact on physiological, psychological, and behavioral outcomes. Antioxidants \& Redox Signaling, 14(2), 275-287. https://doi.org/10.1089/ars.2010.3253

Richardson, J.C., \& Alsup, J. (2015). From the classroom to the keyboard: How seven teachers created their online teacher identities. International Review of Open and Distributed Learning, 16(1), 142-167. https://doi.org/10.19173/irrodl.v16i1.1814

Robertson, I., Cooper, C., Sarkar, M., \& Curran, T. (2015). Resilience training in the workplace from 2003-2014: A systematic review. Journal of Occupational and Organizational Psychology, 88(3), 533-562. https://doi.org/10.1111/joop.12120

Ruder, B., Plaza, D., Warner, R., \& Bothwell, M. (2018). STEM women faculty struggling for recognition and advancement in a "men's club" culture. In C.Cho, J. Corkett, \& A. Steele (Eds.). Exploring the Toxicity of Lateral Violence and Microaggressions (pp.121-149). Cham, Switzerland: Palgrave-MacMillan. https://doi.org/10.1007/978-3-319-74760-6_7

Sarris, J., Logan A. C., Akbaraly, T. N., Amminger, G. P., Balanza-Martinez, V., Freeman, M. P., ... Jacka, F. N. (2015). Nutritional medicine as mainstream in psychiatry. The Lancet Psychiatry, 2, 271-274. https://doi.org/10.1016/S2215-0366(14)00051-0

Seirup, H.J., Tirotta, R., \& Blue, E. (2016). Online education: Panacea or plateau. Journal for Leadership and Instruction, 15(1), 5-8. Retrieved from https://files.eric.ed.gov/fulltext/EJ1097549.pdf 
Sherman, S. M., Chen, Y., Fingerman, K. L., \& Schnyer, D. M. (2016). Social support, stress and the aging brain. Social Cognitive and Affective Neuroscience, 11(7), 1050-1058. https://doi.org/10.1093/scan/nsv071

Snyder, T.D., de Brey, C., \& Dillow, S. (2018). Digest of Education Statistics, 2016. [NCES 2017094]. Washington DC: National Center for Education Statistics. Retrieved from https://nces.ed.gov/pubs2017/2017094.pdf

Sørensen, S. Ø. (2017). The performativity of choice: Postfeminist perspectives on work-life balance. Gender, Work \& Organization, 24(3), 297-313. https://doi.org/10.1111/gwao.12163

Southwick, S. M., \& Charney, D. S. (2012). The science of resilience: Implications for the prevention and treatment of depression. Science, 338, 79-82. https://doi.org/10.1126/science.1222942

Steinberg, S. (2017). The American Academic Profession eBook. New York: Routledge. https://doi.org/10.4324/9781351305808

Stupnisky, R.H., Weaver-Hightower, M.B., \& Kartoshkina, Y. (2015). Exploring and testing the predictors of new faculty success: A mixed methods study. Studies in Higher Education: 40(2), 368-390. https://doi.org/10.1080/03075079.2013.842220

Tabibnia, G., Lieberman, M. D., \& Craske, M. G., (2008). The lasting effect of words on feelings: Words may facilitate exposure effects to threatening images. Emotion, 8, 307-317. https://doi.org/10.1037/15283542.8.3.307

Tabibnia, G., \& Radecki, D. (2018). Resilience training that can change the brain. Consulting Psychology Journal: Practice and Research, 70(1), 59-88. https://doi.org/10.1037/cpb0000110

Tiedt, J.A. (2015). Theoretical perspectives on aging and physical changes. In B.B. Howe (Ed.). The gerontology nurse's guide to the community-based health network (pp. 57-76). New York: Springer.

Topp, R., Hershberger, P.E., \& Bratt, M. (2017). Answering wicked questions: Dealing with opposing truths as a nursing associate professor. Western Journal of Nursing Research, 39(6), 733-744. https://doi.org/10.1177/0193945916687544

Tourangeau, A.E., Wong, M., Saari, M., \& Patterson, E. (2015). Generation-specific incentives and disincentives for nurse faculty to remain employed. Journal of Advanced Nursing, 71(5), 1019-1031. https://doi.org/10.1111/jan.12582

Wilton, S., \& Ross, L. (2017). Flexibility, sacrifice and insecurity: A Canadian study assessing the challenges of balancing work and family in academia. Journal of Feminist Family Therapy, 29(1-2), 66-87. https://doi.org/10.1080/08952833.2016.1272663

Wright, M., \& Hill, L.H. (2015). Academic incivility among health science faculty. Adult Learning, 26(1), 14-20. https://doi.org/10.1177/1045159514558410

Yordy, K. A. (2018). The effects of career related stress on faculty work-life balance: A quantitative analysis (Order No. 10790351). Available from ProQuest Dissertations \& Theses Global A\&I: The Humanities and Social Sciences Collection. (2049675774). 
Address author correspondence to:

Joan M. Owens, Ph.D., RNC

Assistant Professor of Nursing

Gonzaga University

502 East Boone Avenue

Spokane, WA 99258-0102

owensj@gonzaga.edu 